\title{
Mechanisms of Dopaminergic and Serotonergic Neurotransmission in Tourette Syndrome: Clues from an In Vivo Neurochemistry Study with PET
}

\author{
Dean F Wong*,1,2, James R Brašić', Harvey S Singer', David J Schretlen², Hiroto Kuwabara', Yun Zhou', \\ Ayon Nandi', Marika A Maris', Mohab Alexander', Weiguo Ye', Olivier Rousset', Anil Kumar', Zsolt Szabo', \\ Albert Gjedde ${ }^{4}$ and Anthony A Grace ${ }^{5}$ \\ 'Division of Nuclear Medicine, Russell H Morgan Department of Radiology and Radiological Science, Baltimore, MD, USA; ${ }^{2}$ Department of \\ Psychiatry and Behavioral Sciences, Johns Hopkins University, Baltimore, MD, USA; ${ }^{3}$ Department of Neurology, Johns Hopkins University School of \\ Medicine, Johns Hopkins University, Baltimore, MD, USA; ${ }^{4}$ PET Center and Center of Functionally Integrative Neuroscience, Aarhus City Hospital, \\ Aarhus University, Aarhus, Denmark; ${ }^{5}$ Departments of Neuroscience, Psychiatry, and Psychology, University of Pittsburgh, Pittsburgh, PA, USA
}

\begin{abstract}
Tourette syndrome (TS) is a neuropsychiatric disorder with childhood onset characterized by motor and phonic tics. Obsessivecompulsive disorder (OCD) is often concomitant with TS. Dysfunctional tonic and phasic dopamine (DA) and serotonin (5-HT) metabolism may play a role in the pathophysiology of TS. We simultaneously measured the density, affinity, and brain distribution of dopamine $D_{2}$ receptors $\left(D_{2}-R\right.$ 's), dopamine transporter binding potential $(B P)$, and amphetamine-induced dopamine release (DA $\left.A_{\text {rel }}\right)$ in 14 adults with TS and 10 normal adult controls. We also measured the brain distribution and BP of serotonin 5- $\mathrm{HT}_{2 \mathrm{~A}}$ receptors (5$H T_{2 A} R$ ), and serotonin transporter (SERT) BP, in II subjects with TS and 10 normal control subjects. As compared with controls, DA rel was significantly increased in the ventral striatum among subjects with TS. Adults with TS +OCD exhibited a significant $D_{2}-R$ increase in left ventral striatum. SERT BP in midbrain and caudate/putamen was significantly increased in adults with TS (TS + OCD and TS-OCD). In three subjects with $T S+O C D$, in whom $D_{2}-R, 5-H T_{2 A} R$, and SERT were measured within a 12-month period, there was a weakly significant elevation of $\mathrm{DA}_{\text {rel }}$ and $5-\mathrm{HT}_{2 \mathrm{~A}} \mathrm{BP}$, when compared with TS-OCD subjects and normal controls. The current study confirms, with a larger sample size and higher resolution PET scanning, our earlier report that elevated DA $\mathrm{A}_{\text {rel }}$ is a primary defect in TS. The finding of decreased SERT BP, and the possible elevation in 5-HT $2 \mathrm{~A} R$ in individuals with TS who had increased DA $\mathrm{A}_{\text {rel, }}$ suggest a condition of increased phasic DA rel modulated by low $5-\mathrm{HT}$ in concomitant OCD.

Neuropsychopharmacology (2008) 33, 1239- 2 25।; doi:I0.1038/sj.npp. I30I528; published online 7 November 2007
\end{abstract}

Keywords: PET; Tourette's syndrome; dopamine; serotonin; neurochemistry; brain imaging

\section{INTRODUCTION}

Tourette syndrome (TS) is a childhood disorder characterized by motor and phonic tics that must be present for at least 1 year before diagnosis (American Psychiatric Association, 2004). TS can be diagnosed and differentiated from other disorders by the history obtained from the patient and the family, and the carefully structured observation of the patient both at rest and with stimulation (Scahill et al, 2006). People with TS often have a family history of tics, obsessions, compulsions, attention problems, hyperactivity, and other psychiatric disorders

\footnotetext{
*Correspondence: Dr DF Wong, Johns Hopkins University School of Medicine, 60I North Caroline St, JHOC Room 3245, Baltimore, MD 21287-0807, USA, Tel: + I 410955 8433, Fax: + I 4109550696 , E-mail: dfwong@jhmi.edu

Received 23 February 2006; revised II June 2007; accepted I6 July 2007
}

(Scahill et al, 2006; Murray, 1997). While the symptoms of TS are often exacerbated in adolescence, they may subside in adulthood; however, subsets of adults with TS continue to exhibit the symptoms of the syndrome.

We hypothesize that dysfunctional metabolism of the neurotransmitters dopamine (DA) and serotonin (5-HT) plays a role in the development and maintenance of TS (Wong et al, 2005). Multiple anecdotal reports of beneficial effects of DA antagonists (Singer, 2001), and nicotinic (Shytle et al, 2000; Silver et al, 2000) agents in some people with TS suggest that these neurotransmitters are poorly regulated in TS. There is also some anecdotal evidence that serotonin reuptake inhibitors (ie fluoxetine) can alleviate symptoms as well (Silvestri et al, 1994). The benefits of such agents are not uniformly visible, however, and some people with TS report worsening symptoms upon pharmacologic intervention. Consequently, it is necessary to further explore the pathophysiology of TS symptoms in terms of 
specific and interrelated neurotransmitter systems to develop appropriate and more effective novel interventions.

In the present study, we focus on the DA and 5-HT systems. A tonic/phasic imbalance in the DA system may help to explain the DA pathophysiology associated with TS, as has been proposed in schizophrenia (SCZ) (Grace, 1991). In these studies, we used $\left[{ }^{11} \mathrm{C}\right]$ raclopride (a DA receptor antagonist that competes with endogenous DA for binding to $\mathrm{D}_{2}$ and $\mathrm{D}_{3}$ receptors), and $\left[{ }^{11} \mathrm{C}\right] \mathrm{WIN} 32,428$ (a DA transporter (DAT) antagonist), to measure four DA variables: dopamine $\mathrm{D}_{2}$ receptor density $\left(\mathrm{D}_{2} B_{\max }\right)$, dopamine $\mathrm{D}_{2}$ receptor affinity $\left(\mathrm{D}_{2} K_{\mathrm{D}}\right)$, amphetamine (AMP)-induced $\mathrm{DA}$ release $\left(\mathrm{DA}_{\text {rel }}\right)$, and DAT binding potential (BP). Consequently, the current study, via measurement of the DA system, is designed to assess the tonic/phasic regulation hypothesis in relation to TS. The tonic/phasic regulation hypothesis asserts that the low level of tonic extracellular DA, released by the action of corticostriatal afferents, downmodulates spike-dependent phasic $\mathrm{DA}_{\text {rel }}$ in TS, via the activation of autoreceptors on DA terminals (Grace, 1995).

A factor adding a layer of complexity to our understanding of TS is the frequent co-morbidity of TS with obsessive-compulsive disorder (OCD), and the multiple serotonergic abnormalities seen in OCD could reflect the presence of dysfunctional 5-HT neurotransmission in TS. In traditional pharmacotherapy, people with TS often respond preferentially to DA antagonists (Singer, 2001), whereas people with OCD respond mainly to selective serotonin reuptake inhibitors (SSRIs). This variation suggests different pathophysiologies for these disorders; however, it has been reported that mixed serotonergic/dopaminergic agents such as risperidone help alleviate symptoms of TS and OCD (McDougle et al, 2000; Pfanner et al, 2000). Therefore, in this study, we also evaluated the $\mathrm{BP}$ of serotonin $5-\mathrm{HT}_{2 \mathrm{~A}}$ receptors (5- $\mathrm{HT}_{2 \mathrm{~A}} \mathrm{R}$ 's), as well as the $\mathrm{BP}$ of serotonin transporter (SERT), using the radiotracers $\left[{ }^{11} \mathrm{C}\right] \mathrm{McN} 5652$ (a 5- $\mathrm{HT}_{2 \mathrm{~A}} \mathrm{R}$ antagonist) and $\left[{ }^{11} \mathrm{C}\right] \mathrm{MDL} 100,907$ (an SERT antagonist). For people with TS, firm evidence of either a 5HT/alone or DA/5-HT abnormality would provide support for-or raise questions about-treatment combinations utilizing DA and 5-HT antagonism, such as exerted by atypical neuroleptics.

\section{METHODS}

\section{Participants}

Healthy adult control subjects were recruited via advertisements in local newspapers, word of mouth, and announcements at local universities. Adult subjects with TS were recruited with the help of local and regional chapters of the Tourette Syndrome Association. All subjects received thorough medical and psychiatric screenings, which specifically examined current and earlier medications. All subjects were free of neuroleptic, serotonergic, and dopaminergic drugs at the time of PET scanning, and had been treatment-free for a period of at least 6 months before the start of the study.

Study procedures were conducted in accordance with the Declaration of Helsinki Principle of 2004. The Institutional Review Board of The Johns Hopkins University School of
Medicine approved the studies and the informed consent documents. All participants gave their written informed consent.

Dopamine study. For the DA study, we recruited and performed PET scans on a total of 14 subjects with TS (12 M, $2 \mathrm{~F}$, age $29 \pm 8$ (SD) years) and 10 normal controls (6 M, $4 \mathrm{~F}$, age $26 \pm 7$ (SD) years). Seven of the subjects with TS were treatment naïve, three were not currently on medication, and the remaining four subjects voluntarily stopped their medication at least 6 months before the baseline PET scan.

Serotonin study. For the 5-HT study, we recruited and performed PET scans on a total of 11 subjects with TS ( $9 \mathrm{M}$, $2 \mathrm{~F}$, age $34 \pm 9(\mathrm{SD})$ years) and 10 normal controls $(5 \mathrm{M}, 5 \mathrm{~F}$, age $32 \pm 8$ (SD) years). Eight of the subjects with TS were treatment naïve, two were not currently on medication, and the remaining subject voluntarily stopped medication at least 6 months before the baseline PET scan.

\section{General Procedures}

Participants were enrolled as outpatients in the Division of Nuclear Medicine of Johns Hopkins Hospital. Participants were required to abstain from use of all psychoactive drugs, caffeine, alcohol, and nicotine for the days of the PET scans. All subjects underwent medical history and physical examinations, which included full toxicology and blood workups. In the female participants, urine pregnancy tests were given before and during study participation, and all the results of all pregnancy tests were negative. Subjects also underwent 12-lead electrocardiography (ECG).

For Tourette's subjects, we used the DSM-IV-TM ${ }^{\mathrm{TM}}$ (American Psychiatric Association, 2004) as the inclusion criteria. We also required that all subjects be drug naïve or drug-free for at least 3 months. Exclusion criteria included any marked axis I psychiatric disorder, order than TS with or without OCD, as well as any movement disorder other than those resulting from TS or OCD.

\section{Neurocognitive Battery and Neuropsychiatric Assessments}

All subjects received an evaluation of overall neurocognitive functioning during screening, and further neuropsychiatric assessments during a separate study day. Neurocognitive testing was conducted in a quiet testing room. The complete battery was designed to assess intelligence, executive functioning, word and design fluency, new learning/ memory and visual constructional ability.

A comprehensive family history, with emphasis on tics and neuropsychiatric problems including OCD, was also obtained on a separate day from the PET scans. OCD was diagnosed according to the Structured Clinical Interview for DSM-IV Axis I Disorders (SCID-I), Clinical Version. The presence and severity of obsessions and compulsions were measured by the Yale-Brown Obsessive-Compulsive Scale (Y-BOCS) (Goodman et al, 1989a, b). The diagnosis of adult Attention Deficit and Hyperactivity Disorder was determined by the Clinical Global Impression Scale for Attention Deficit Disorder (Guy, 1976) and the Wender Utah Rating 
Scale (WURS) (Wender, 1995). In addition, the Yale Global Tic Severity Scale (YGTSS) (Leckman et al, 1989) and the Brief Psychiatric Rating Scale (BPRS) (Overall and Gorham, 1962) were administered to 14 subjects with TS (12 M, $2 \mathrm{~F}$, age $29 \pm 8(\mathrm{SD})$ years) and 10 normal controls ( $6 \mathrm{M}, 4 \mathrm{~F}$, age $26 \pm 7$ (SD) years) for the DA study, and 11 subjects with TS (9 M, 2 F, age $34 \pm 9$ (SD) years) and 10 normal controls ( $5 \mathrm{M}, 5 \mathrm{~F}$, age $32 \pm 8$ (SD) years) for the 5-HT study.

\section{Dopamine Measurements}

To obtain measurements of DA dynamics, including $\mathrm{DA}_{\text {rel }}$, $\mathrm{D}_{2} B_{\max }$, and $\mathrm{D}_{2} K_{\mathrm{D}}$, subjects were scanned over two study days, and received two PET scans each day according to the following procedure: day 1-Scan 1 : $\left[{ }^{11} \mathrm{C}\right]$ raclopride: pretreatment: intravenous (i.v.) saline bolus $(5 \mathrm{cc}$ over $3 \mathrm{~min}$ at 5 -min pre-injection). Day 1-Scan 2: $\left[{ }^{11} \mathrm{C}\right]$ raclopride: pretreatment: i.v. AMP bolus $(0.3 \mathrm{mg} / \mathrm{kg}$ over $3 \mathrm{~min}$ at 5 -min pre-injection). Day 2-Scan 3 (within 7 days post-day 1): $\left[{ }^{11} \mathrm{C}\right]$ WIN35,428 $\left(\left[{ }^{11} \mathrm{C}\right] \mathrm{WIN}\right)$ : i.v. push bolus. Day 2-Scan 4: $\left[{ }^{11} \mathrm{C}\right]$ raclopride (low-specific activity): i.v. push bolus.

On day 1 , the specific activity of $\left[{ }^{11} \mathrm{C}\right]$ raclopride for Scan 1 and Scan 2 averaged $10000-15000 \mathrm{mCi} / \mu \mathrm{mol}$, average mass of $1.0 \mu \mathrm{g}$, with a dose of approximately $20 \mathrm{mCi}$. On day 2 , the specific activity of $\left[{ }^{11} \mathrm{C}\right]$ WIN averaged $10000-$ $15000 \mathrm{mCi} / \mu \mathrm{mol}$, average mass dose of $1.0 \mu \mathrm{g}$, with a dose of approximately $20 \mathrm{mCi}$. The low-specific activity of $\left[{ }^{11} \mathrm{C}\right]$ raclopride on day 2 averaged $1000-1500 \mathrm{mCi} / \mu \mathrm{mol}$, with a mass of 300-600 $\mu \mathrm{g}$. Thus, Scan 1 and Scan 2 measured $\mathrm{DA}_{\text {rel }}$, Scan 3 measured the BP of WIN for DAT, and Scan 1 and Scan 4 yielded the $\mathrm{D}_{2} B_{\max }$ and $\mathrm{D}_{2} K_{\mathrm{D}}$ measures.

\section{Serotonin Measurements}

To obtain measurements of SERT and $5-\mathrm{HT}_{2 \mathrm{~A}} \mathrm{R}$ BPs, subjects received two PET scans on the same day. The first scan used the radiotracer $\left[{ }^{11} \mathrm{C}\right] \mathrm{McN} 5652(\mathrm{McN})$, for SERT, and the second scan used the radiotracer $\left[{ }^{11} \mathrm{C}\right] \mathrm{MDL} 100,907$ (MDL) for 5-HT2A; each a 95-min PET scan i.v. push bolus with a dose of approximately $20 \mathrm{mCi}$ and high-specific activity ( $>2000 \mathrm{Ci} / \mathrm{mmole}$ ).

\section{PET Procedures}

For all scans, the same general PET and image analysis procedures were followed. For co-registration with the PET data to enhance anatomical definitions, each participant received a volumetric magnetic resonance imaging (MRI) scan with analysis of the caudate, putamen and ventral striatum to ensure that regional brain volumetric differences did not account for any of the PET analysis results. The MRI data were acquired using a spoiled GRASS (gradient recalled acquisition in steady state) (SPGR) sequence on a GE 1.5T Signa Camera (GE Healthcare, Chalfont St Giles, UK). To minimize movement during the MRI and PET scans, each participant was custom-fitted with a thermoplastic face mask.

Upon arrival to the PET center, a venous catheter was placed in the antecubital vein for injection of the radiotracer. $\left[{ }^{11} \mathrm{C}\right]$ raclopride (Ehrin et al, 1985) or $\left[{ }^{11} \mathrm{C}\right] \mathrm{WIN}$ (Wong et al, 1993), produced at the Johns Hopkins Hospital
Biomedical Cyclotron, was injected at the start of PET scanning. An arterial catheter was placed in the opposite arm as the venous line for blood sampling during all scans. All subjects received ECG, blood pressure, and pulse rate monitoring during each scan.

PET images were obtained on a GE Advance PET camera (GE Healthcare), which simultaneously acquires 35 slices, with an axial field of view of $15.2 \mathrm{~cm}$. Each PET session consisted of a 90 -min scan, with 32 frames of 15 -s to $5 \mathrm{~min}$ each, according to the following protocol: four 15-s frames, four 30-s frames, three 1-min frames, two 2-min frames, five 4-min frames, twelve 5-min frames. Data were acquired in the three-dimensional mode. The images were reconstructed using filtered back-projection with a ramp filter (image size $128 \times 128$, pixel size $2 \times 2 \mathrm{~mm}^{2}$, inter-slice spacing $4.25 \mathrm{~mm}$ ), resulting in a spatial resolution of $5.5 \mathrm{~mm} \times 5.5 \mathrm{~mm} \times 4.25 \mathrm{~mm}$ full-width-at-half-maximum at the center of the field of view. Data in the decaycorrected, reconstructed, dynamic images were expressed in units of concentration $(\mu \mathrm{Ci} / \mathrm{ml})$.

\section{Image Analysis}

For all PET scans, the initial primary outcome was BP, representing a ratio of receptor density divided by receptor affinity $\left(B_{\max } / K_{\mathrm{D}}\right)$ (Logan et al, 1996). Thus, for the three $\left[{ }^{11} \mathrm{C}\right]$ raclopride scans (Scans 1,2 , and 4 ), BP represents the $B_{\max } / K_{\mathrm{D}}$ of raclopride for $\mathrm{D}_{2} / \mathrm{D}_{3}$ receptors. For the $\left[{ }^{11} \mathrm{C}\right]$ WIN scan (Scan 3), BP represents the $B_{\max } / K_{\mathrm{D}}$ for DAT. Intrasynaptic $\mathrm{DA}_{\text {rel }}$ was defined as the displacement of $\left[{ }^{11} \mathrm{C}\right]$ raclopride by endogenous $\mathrm{DA}$, and was calculated as the percent change in BP for the post-AMP challenge $\left[{ }^{11} \mathrm{C}\right]$ raclopride scan (Scan 2) and the baseline BP measured in the post-saline $\left[{ }^{11} \mathrm{C}\right]$ raclopride scan (Scan 1). The $\mathrm{D}_{2} B_{\max }$ was calculated from the BP at high-specific (Scan 1) and low-specific (Scan 4) activity $\left[{ }^{11} \mathrm{C}\right]$ raclopride for absolute receptor density, using two methods: true receptor equilibrium measures of binding and ligand exchange (TREMBLE; Sölling et al, 1997) and the transient equilibrium method (TEM; Farde et al, 1989). To determine BP, volumes of interest (VOIs) were drawn for subdivisions of the striatum and used to extract time-activity curves, as described below.

VOI definition. VOIs were manually defined for the caudate nucleus, putamen, and cerebellum on each individual's MRI. The VOIs were measured $(\mathrm{ml})$ to test for differences in brain volumetrics between patient groups. The striatal VOIs were divided into five functional divisions (Martinez et al, 2003), using the anatomical guidance provided by postmortem studies of human brain (Karachi et al, 2002) to overcome the fact that the subdivisions were not identifiable on MRI alone. Ventral striatum was separated from the other striatal VOIs on each coronal image after reorienting the MRI such that the anterior/posterior commissural plane (AC/PC) was horizontal. For this procedure, a line was placed on each coronal image that was perpendicular to the bisector of the internal capsule and passed through the lower corner of the lateral ventricle (Baumann et al, 1999). We defined the ventral striatum as the portions of striatal VOIs that were below the line. The caudate and putamen VOIs were classified into respective anterior and posterior 
subdivisions by the $\mathrm{AC} / \mathrm{PC}$ plane in the reoriented MRI (Baumann et al, 1999; Karachi et al, 2002; Martinez et al, 2003). Thus, we sampled 10 subdivisions of the striatum: anterior and posterior regions of both the putamen and the caudate nucleus, and the ventral striatum, each in both the left and right hemispheres. The cerebellum VOI was used as a reference region.

The VOIs were transferred to PET space according to MRI-to-PET co-registration parameters using the mutual information theory as implemented in SPM2. Time-activity profiles of regions were obtained by applying the VOIs to individual PET frames after correcting for movements of the head during PET scans (Meyer et al, 1999).

\section{Mathematical Modeling}

$B P, \mathrm{~B}_{\max }$ and $D A_{\text {rel }}$ for $\left[{ }^{11} C\right]$ raclopride. We employed a simplified reference tissue approach (SRTM) (Lammerstma and Hume, 1996), as modified to a linear operational equation (Ichise et al, 2003), and a reference tissue graphical analysis (RTGA; Logan et al, 1996). BP was also calculated for $\left[{ }^{11} \mathrm{C}\right]$ raclopride using TREMBLE, which calculates the BP at the peak bound/free ratio (Sölling et al, 1997). $\mathrm{D}_{2}$ receptor $\left(\mathrm{D}_{2}-\mathrm{R}\right)$ occupancy due to i.v. AMP challenge was calculated as $\mathrm{DA}_{\text {rel }}=($ Baseline BP-post AMP BP $) /$ Baseline and expressed as a percentage. TREMBLE (Wong et al, 1998), as well as TEM (Farde et al, 1989), was used to calculate $\mathrm{D}_{2} B_{\max }$ and $K_{\mathrm{D}}$.

The TEM analysis was performed as follows: it was assumed that the radioactivity concentration of bound ligand at time $t$ was obtained by $\mathrm{A}(t)$ minus $\mathrm{R}(t)$ where $\mathrm{A}(t)$ and $\mathrm{R}(t)$ were the radioactivity concentrations at time $t$ for the target and reference regions. Transient equilibrium $(\mathrm{dB}(t) / \mathrm{d} t=0)$ was assumed when $\mathrm{B}(t)$ reached the maximum $\left(=t_{0}\right)$. We predicted $\mathrm{A}(t)$ using the multi-linear reference tissue method with two parameters (MRTM2; Ichise et al, 2002) to reduce noise in measured $\mathrm{A}(t)$. The bound-free ratio $\left(\mathrm{B}(t)\right.$ over $\mathrm{R}(t)$ at $\left.t_{0}\right)$ was plotted against $\mathrm{B}\left(t_{0}\right)$ for low- and high-specific radioactivity experiments (the Eadie-Hofstee plot) to obtain $\mathrm{D}_{2} B_{\max }$ as the $y$ intercept and $-K_{\mathrm{D}}$ as slope of the line connecting the two points.

BP for $\left[{ }^{11} C\right]$ WIN (DAT BP). We applied a one-vascular, two-tissue compartmental model for $\left[{ }^{11} \mathrm{C}\right] \mathrm{WIN}$ (Wong et al, 1993), using metabolite-corrected plasma radioactivity data, to obtain the BP of DAT.

5-HT modeling methods. The parametric imaging approaches (Zhou et al, 2002a, b, 2003, 2004a, b), including linear and nonlinear least square fitting with spatial constraint, were used to evaluate voxel-wise kinetics for the $\mathrm{McN}$, and MDL dynamic PETs. VOIs were extracted as described above. Parametric images of $K_{1}, D V$, and BP were generated for VOI and voxel statistical analysis using SPM (Zhou et al, 2002b).

\section{Statistical Analysis}

Statistical analysis of all PET parameters for 5-HT and DA measures $\left(B_{\max }, K_{\mathrm{D}}, \mathrm{BP}\right)$ and $\mathrm{DA}_{\text {rel }}$, DAT, SERT: means and SD were calculated for $\mathrm{BP}$ and change in receptor occupancy for each striatal VOI for both controls and all patient groups. Since the cerebellum VOI was the reference region, it was not included in the statistical analysis. To test for between-groups differences, we used a robust linear regression model, where group status (ie control vs TS) was encoded using dummy variables, and set as the independent variable. The PET parameters were set as the dependent variables, with age as a covariate.

To test for correlations between PET parameters and scores from psychiatric scales, individual values for those variables were incorporated into a linear regression. All statistical analyses were performed using Stata 8 (StataCorpLP, College Station, TX, USA).

\section{RESULTS}

\section{Dopamine Hypotheses}

Based on previous findings of elevation in $\mathrm{DA}_{\text {rel }}$ (Singer et al, 2002) and $B_{\max }$ (Wong et al, 1997), we hypothesized that the TS groups would continue to show elevations of DA parameters in striatal regions. Changes in DA parameters were tested at each striatal VOI using robust linear regression as described above.

\section{$D_{2}$ Receptors}

Twelve subjects with TS (10 M, 2 F, age: $31 \pm 8.9$ (SD)) and three normal control subjects ( $1 \mathrm{M}, 2 \mathrm{~F}$, age: $24 \pm 2.5$ (SD)) completed Scans 1-4, and results were compared across three variables describing the $\mathrm{D}_{2}-\mathrm{R}$ system: $\mathrm{BP}, K_{\mathrm{D}}$, and $B_{\max }$, using TREMBLE analysis. Although a small control group, only subjects whose plasma radioactivity and metabolites were available to construct time-activity curves were used (requires insertion of an arterial catheter for blood collection).

Baseline BP was not different between subject groups in any brain region $(p>0.05)$. With the TEM method used for modeling, subjects with TS showed lower $B_{\max }$ values than normal controls in the left anterior putamen $(p=0.02)$. There was also a weakly significant decrease in the right anterior putamen $(p=0.07)$ and right posterior putamen $(p=0.06)$. Overall, TS subjects showed a uniform decrease in $B_{\max }$ across all brain regions as compared to controls. With $K_{\mathrm{D}}$, we also saw a significant decrease in TS subjects as compared to control in the left and right anterior putamen $(p=0.03)$. A decrease in $K_{\mathrm{D}}$ is also seen in the left ventral striatum, but at weaker significance $(p=0.09)$ (Figure 1).

\section{$\mathrm{DA}_{\text {rel}}$, A Measure of Receptor Occupancy}

The group comparison shows a robust increase of $\mathrm{DA}_{\text {rel }}$ in the right ventral striatum $(p<0.05)$, in 14 subjects with TS (12 M, $2 \mathrm{~F}$, age $29 \pm 8$ (SD) years), as compared with 10 healthy controls (6 M, 4 F, age $26 \pm 7$ (SD) years; Figure 2). A weakly significant increase in $\mathrm{DA}_{\text {rel }}$ was also seen in left ventral striatum of subjects with TS, when compared with controls $(p=0.06) . \mathrm{DA}_{\text {rel }}$ in the TS group was nearly double that of the control group.

\section{DA Transporter}

DAT BP was obtained for 11 subjects with TS $(9 \mathrm{M}, 2 \mathrm{~F}$, age $32 \pm 8(\mathrm{SD})$ ) years) and five normal controls (3 M, $2 \mathrm{~F}$, age 

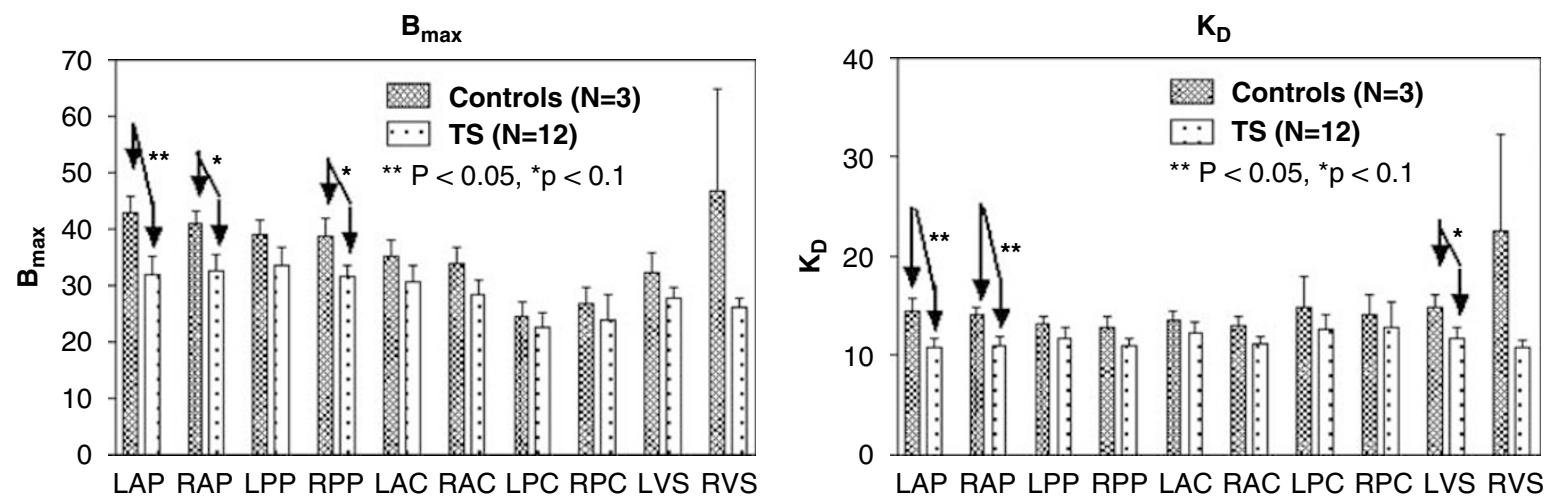

Figure I Dopamine receptor $B_{\max }$ and $K_{D}$ in Subjects with Tourette syndrome and normal controls. Receptor density $\left(B_{\max }\right)$ and affinity $\left(K_{D}\right)$ were measured using the transient equilibrium method (TEM; Farde et al, 1989), in subjects with TS and normal controls. The TEM method showed significant contrasts for $B_{\max }$ and $K_{D}$ in the putamen, indicated by the double asterices ventral striatum. We also see weakly significant contrasts in the ventral striatum, indicated by the single asterisk.
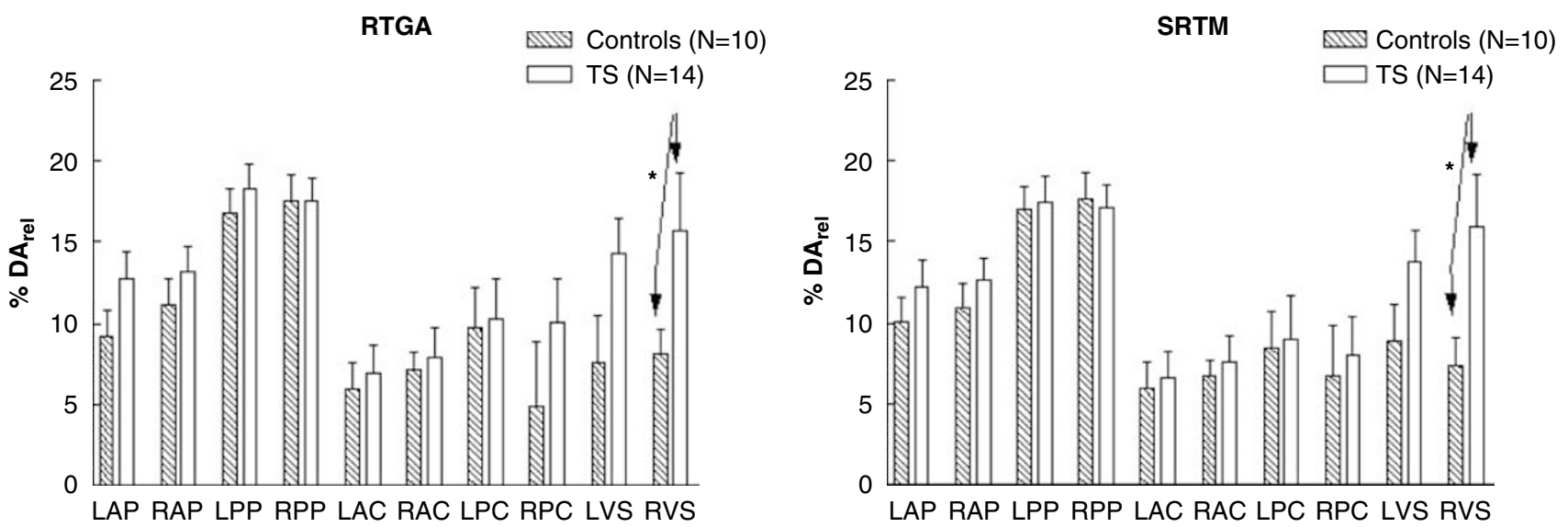

Figure $2 D_{\text {rel }}$ in subjects with Tourette syndrome and normal controls by the SRTM and RTGA methods. Dopamine release (DA rel) is calculated using two mathematical modeling methods: the simplified reference tissue method (SRTM; Lammerstma and Hume, 1996), and the reference tissue graphical analysis (RTGA; Logan et al, 1996). Both methods demonstrate a significant elevation (approximately 50\%) of DA rel $_{\text {in }}$ the left and right ventral striatum, in subjects with Tourette syndrome (TS), as compared with normal controls. Asterisks indicate significant contrasts; $p<0.05$.

$25 \pm 4$ (SD) years), and was measured using data from the WIN scan (Scan 3). No significant differences were seen in DAT BP between subjects with TS and normal controls in any brain region $(p>0.05$; Figure 3$)$.

\section{5-HT Measures}

BPs for both $5-\mathrm{HT}_{2 \mathrm{~A}}$ and SERT were compared between TS and control groups, as well as among the TS group subsets (TS + OCD $(n=9)$; TS-OCD $(n=2)$ ) and normal controls $(n=9$, Figure 4). Significant reductions were seen in SERT BP in the midbrain, caudate, and putamen of subjects with TS, when compared with normal controls $(p<0.05$; Figure 4a). When SERT BP was compared among the TS + OCD, TS-OCD, and control groups, significant decreases were seen in TS + OCD $(p<0.05)$ and TS-OCD $(p<0.05)$, as compared with normal controls in the midbrain (Figure $4 \mathrm{~b}$ ).

No significant differences were noted in $5-\mathrm{HT}_{2 \mathrm{~A}} \mathrm{BP}$ in any brain region when comparing the TS and control groups (Figure 4c), but weakly significant elevations in $5-\mathrm{HT}_{2 \mathrm{~A}} \mathrm{BP}$ were observed in TS + OCD $v$ s TS-OCD $(p=0.07)$, and TS +
OCD $v s$ normal controls $(p=0.08)$, in pre-frontal, temporal, and cingulate cortices (Figure $4 \mathrm{~d}$ ).

\section{Neuropsychological Assesments}

The following correlations between $\mathrm{DA}_{\text {rel }}$ (as measured by RTGA) and neuropsychological assessments in subjects with TS were significant and of interest. $\mathrm{DA}_{\text {rel }}$ in the left ventral striatum was significantly and positively correlated with interpersonal sensitivity $t$-score $(r=0.6, p=0.038)$. When the same correlation analysis was applied to $\mathrm{DA}_{\text {rel }}$ measurements using SRTM, the results were marginally significant, but still showed a positive correlation $(r=0.5$, $p=0.06)$.

\section{Neuropsychiatric Assessments}

A brief summary of the neuropsychiatric assessments is presented by study (DA and 5-HT) in Table 1, including results of the BPRS, the YGTSS, the Y-BOCS, and the WURS (Tables 2 and 3). 


\section{MRI Findings}

Volumetric MRI changes have been noted in TS, in that children with TS have shown to have a predominance of the right putamen over normal controls (Singer et al, 1993). Thus, in the current study, the putamen, caudate, and ventral striatum were assessed in 14 subjects with TS and 8 normal controls to ensure that volumetric disparities did

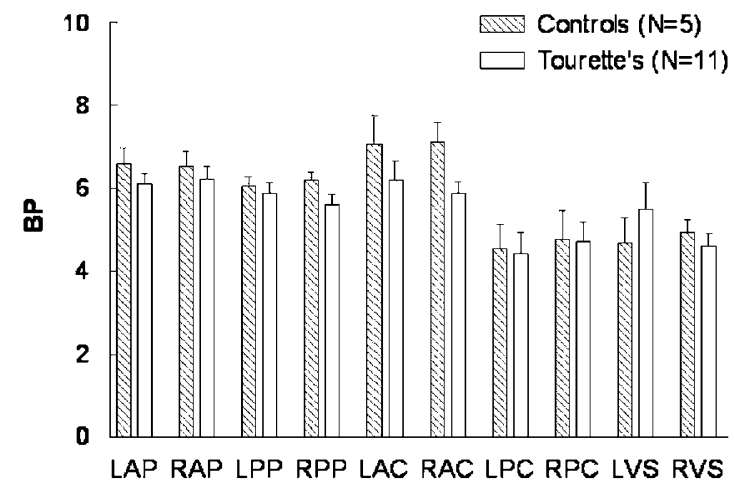

Figure 3 DAT binding potential in subjects with Tourette syndrome and healthy controls. No significant differences were seen in measurements of DAT binding potential between subjects with TS, as compared with normal controls, in any brain region ( $p>0.05)$.

not account for any group differences observed in the PET results. However, no significant differences in regional brain volumes were found between patient groups $(p>0.05)$. In addition, no significant left-right asymmetries were observed in either population ( $p>0.05$; data not shown).

\section{LIMITATIONS}

\section{Use of McN to Measure SERT}

An increasing number of publications have used the tracer DASB to measure SERT, because DASB does have higher contrast than McN (McCann et al, 2005). However, we are not aware of any published studies showing any clinical advantage of DASB over McN. While the increased contrast with DASB has led to an increase in the number of studies with DASB vs McN, McN is as well suited to display the SERT and its losses as DASB.

Furthermore, we have published two papers (McCann et al, 2005; Szabo et al, 2002) in which we compared the kinetics of the two tracers including arterial blood collection and compartmental modeling. In a preclinical study on baboons treated with MDMA, both radioligands demonstrated reduced binding in all brain regions and the correlation between them was very high. Also in a clinical paper on MDMA users and matched control subjects the
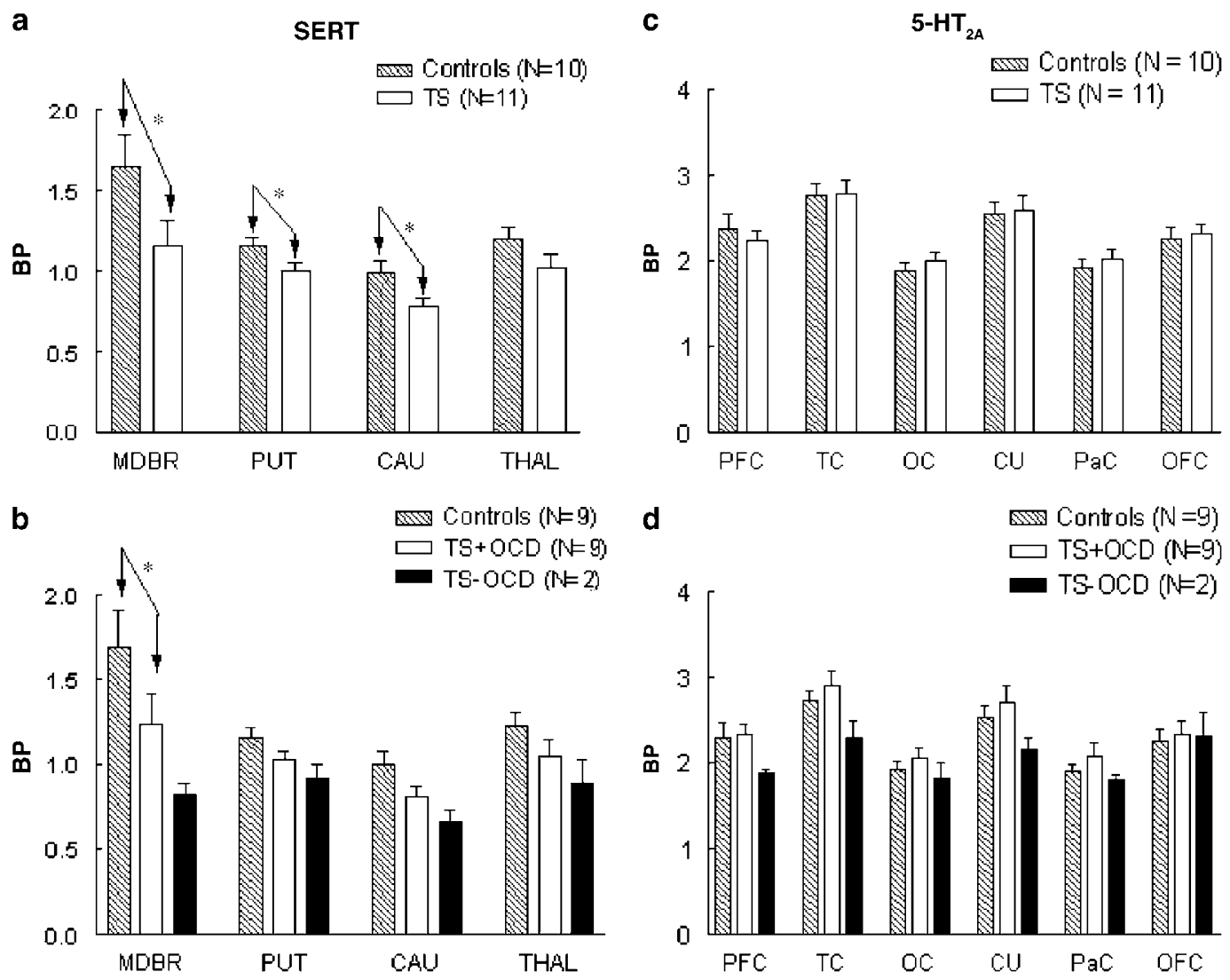

Figure 4 SERT and 5- $\mathrm{HT}_{2 A} \mathrm{R}$ binding potentials (BPS) in TS + OCD and TS-OCD subjects, and normal controls. (a) Significant reductions (*P $<0.05$ ) were seen in serotonin transporter (SERT) BP in the midbrain, caudate, and putamen of subjects with Tourette syndrome (TS), when compared with normal controls. (b) When grouped by OCD status, the TS + OCD groups displayed significant decreases in SERT BP in midbrain, as compared with normal controls (* $p<0.05)$. (c) No significant differences were seen in serotonin receptor $\left(5-H_{2 A} R\right) B P$ between TS and normal controls $(p>0.05)$. (d) When grouped by OCD status, TS + OCD subjects showed slightly higher $5-\mathrm{HT}_{2 \mathrm{~A}}$ binding, but these results were not significant $(p>0.1)$. 
Table I Summary of Clinical Evaluations of Subjects with TS and Healthy Controls

YGTSS

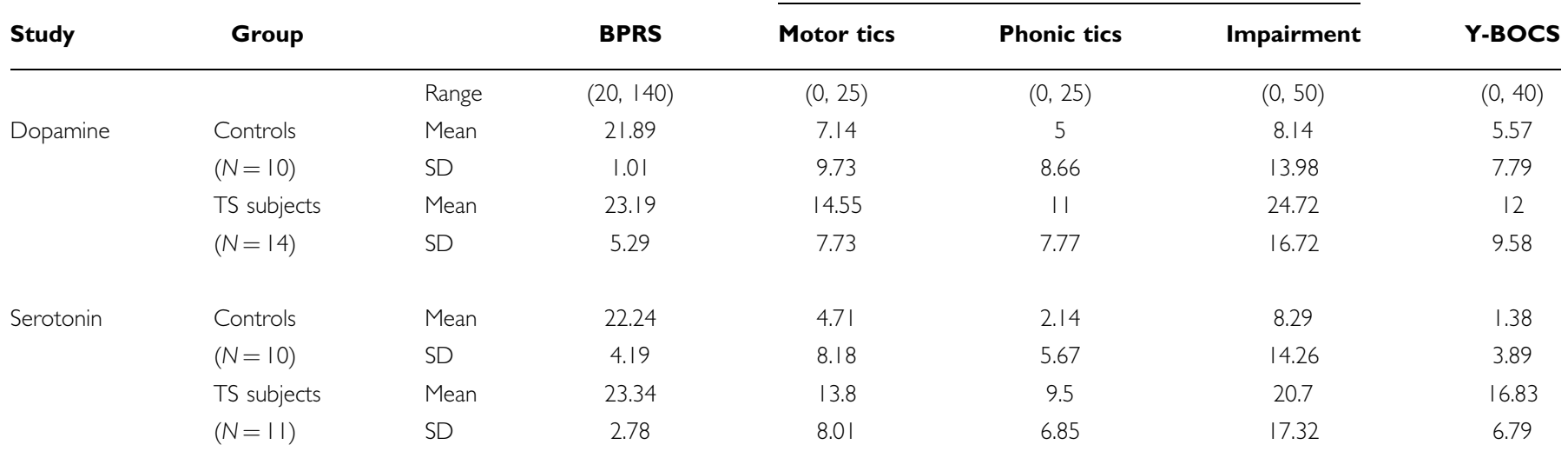

BPRS, brief psychiatric rating Scale (Overall and Gorham, 1962); TS, Tourette syndrome; Y-BOCS, Yale-Brown Obsessive Compulsive Scale; YGTSS, Yale Global Tic Severity Scale.

Motor tics, phonic tics, and impairment were measured using the YGTSS (Leckman et al, 1989). The presence and severity of obsessions and compulsions were measured by the Y-BOCS (Goodman et al, 1989a, b). Higher scores indicate worsening phenotype.

Table 2 Study Population Demographics of Subjects with TS and Healthy Controls

\begin{tabular}{|c|c|c|c|c|c|c|}
\hline \multirow[b]{2}{*}{ Study } & \multirow[b]{2}{*}{ Measure } & \multirow[b]{2}{*}{ Group } & \multirow[b]{2}{*}{$N$} & \multirow{2}{*}{$\begin{array}{l}\text { Age } \\
\text { Mean } \\
\text { (SD) }\end{array}$} & \multicolumn{2}{|c|}{ Gender } \\
\hline & & & & & Male & Female \\
\hline \multirow[t]{10}{*}{ Dopamine } & $\mathrm{DA}_{\text {rel }}$ & Controls & 10 & $26(7)$ & 6 & 4 \\
\hline & & TS subjects & 14 & $29(8)$ & 12 & 2 \\
\hline & DAT & Controls & 5 & $25(4)$ & 3 & 2 \\
\hline & & TS subjects & 11 & $32(8)$ & 9 & 2 \\
\hline & $D_{2}$ receptors & Controls & 7 & $26(6)$ & 3 & 4 \\
\hline & & TS subjects & 11 & $30(9)$ & 9 & 2 \\
\hline & Neuropsychiatric & Controls & 10 & $26(7)$ & 6 & 4 \\
\hline & & TS subjects & 14 & $29(8)$ & 12 & 2 \\
\hline & Neurocognitive & Controls & 9 & $25(6)$ & 5 & 4 \\
\hline & & TS subjects & 14 & $29(8)$ & 12 & 2 \\
\hline \multirow[t]{6}{*}{ Serotonin } & 5- $\mathrm{HT}_{2 \mathrm{~A}} \mathrm{R}$ and SERT & Controls & 10 & $32(8)$ & 5 & 5 \\
\hline & & TS subjects & | | & $34(9)$ & 9 & 2 \\
\hline & Neuropsychiatric & Controls & 10 & $32(8)$ & 5 & 5 \\
\hline & & TS subjects & || & $34(9)$ & 9 & 2 \\
\hline & Neurocognitive & Controls & 2 & $22(1)$ & 0 & 2 \\
\hline & & TS subjects & 7 & $33(7)$ & 6 & । \\
\hline
\end{tabular}

TS, Tourette syndrome.

The following were evaluated in separate populations for the dopamine and serotonin studies. Dopamine study: amphetamine (AMP)-stimulated dopamine release $\left(\mathrm{DA}_{\text {rel }}\right)$; dopamine transporter (DAT) density; the density $\left(B_{\max }\right)$ and affinity $\left(K_{D}\right)$ of $D_{2}$ dopamine receptors. Serotonin study: the density $\left(B_{\max }\right)$ and affinity $\left(K_{D}\right)$ of $5-H_{2}$ serotonin receptors, and serotonin transporter (SERT) density. Neuropsychiatric and neurocognitive measures were evaluated in both populations.

correlation between the two tracers was high. The human study included MDMA users and controls. The correlation between the specific binding component of the distribution volume (DVsp) of 15 brain regions demonstrated high correlation between $\mathrm{McN}$ and DASB in both controls and users (McCann et al, 2005).

\section{Statistical Justification}

Even though we performed several analyses on the given data, we did not use a correction for multiple comparisons. While multiple comparison corrections apply to multiple tests on a single-dependent variable, we performed single tests on multiple, independent end points. That is, each measurement of DAR, $K_{\mathrm{D}}$, etc, in each brain region can be considered an independent experiment. Thus, we used a robust linear regression, treating each derived measurement in each brain region as an independent measurement.

\section{DISCUSSION}

Abnormalities in the DA system have been implicated previously in the pathophysiology of TS. Our own pilot results with seven subjects with TS and five age-matched normal controls showed an increased $\mathrm{DA}_{\text {rel }}$ in subjects with TS (Singer et al, 2002). We have confirmed and extended this initial result in our current study with a doubling of the sample size, and with the use of higher-resolution tomography (GE Advance vs GE 4096 PET) and multiple mathematical modeling methods. Although we were not able to see elevations in $B_{\max }$ in TS as reported previously (Wong et al, 1997), this may be due to the smaller sample size in the current study (12 TS subjects in current study $v \mathrm{~s}$ 20 TS subjects in previous study), as well as the fact that the previous 1997 paper showed the highest elevations in a smaller subgroup of four TS subjects, who may not have been representative of our current TS population.

Ever since the original DA hypothesis for TS was proposed (Singer et al, 1982), the underlying dopaminergic deficit leading to TS dysfunction has eluded investigators. Thus, despite the many attempts to characterize TS, 
including the measurement of homovanilic acid levels in post-mortem studies (Butler et al, 1979; Singer et al, 1982), it appears that the most direct evidence has been the strikingly consistent increase in AMP-induced $\mathrm{DA}_{\text {rel }}$ that was first shown via PET imaging in the pilot study mentioned above (Singer et al, 2002). Improved tomographic resolution has allowed us to examine specific subdivisions of the striatum and, in the current study, we have observed significantly elevated AMP-induced $\mathrm{DA}_{\text {rel }}$ in the ventral striatum. Indeed, this elevation may be more consistent than that reported for AMP-induced $\mathrm{DA}_{\text {rel }}$ in SCZ (Gjedde and Wong, 1998; Laruelle et al, 1996).

\section{Origin of Increased $\mathrm{DA}_{\text {rel }}$ : the Tonic-Phasic DA Model}

The model of the tonic-phasic balance in the DA system as a homeostatic mechanism may also explain the DA pathology in TS. Disruption of the tonic-phasic balance has been proposed to underlie the DA pathophysiology in SCZ (Grace, 1991, 1995) as well as in other neurological disorders, such as TS. This model is based on electrophysiological and neurochemical data, in which two types of DA kinetics exist in postsynaptic targets of the DA system. The long-term or homeostatic mechanism is determined by the tonic 'baseline' level of DA, which is in low concentrations, shows slow changes, and exists extracellularly. This is defined primarily as an extrasynaptic measure, from studies using microdialysis and electrophysiological measurements (O'Donnell and Grace, 1994; West and Grace, 2002). Phasic $\mathrm{DA}$ is the spike-dependent $\mathrm{DA}_{\text {rel }}$ that occurs primarily into the synapse; it will cause transient, local changes in the vicinity of the synaptic cleft with sufficient simulation (Wightman and Robinson, 2002) or when an uptake blocker is given (eg AMP) (Grace, 1991, 1995). Intrasynaptic $\mathrm{DA}_{\text {rel }}$ produced by spike-dependent $\mathrm{DA}_{\text {rel }}$ or from the use of stimulant challenges such as AMP has been proposed as a surrogate for phasic DA. Therefore $\mathrm{DA}_{\text {rel }}$ excludes the lowlevel tonic extrasynaptic DA levels that indirectly may influence the phasic release.

Grace $(1991,1995)$ has proposed that DA is modulated by baseline levels of tonic (extrasynaptic) DA, which may be regulated by neocortical afferents and by DAT. While we found no changes in DAT binding, previous studies (Malison et al, 1995; Singer et al, 1991) have reported increased DAT binding, which fits the Grace $(1991,1993)$ models of dysfunctional regulation of tonic DA in TS.

We believe that this type of functional regulatory system is a potential target for the types of disruption that may underlie regulatory disorders of the brain, including disorders such as TS, SCZ, or depression (Grace, 1993). We suggest that in TS, the clinical and imaging evidence is consistent with the decreased tonic regulation of phasic DA response, and that this leads to a hyper-responsive spikedependent DA-releasing system and subsequent pathological states. This increased release, coupled with other yet-tobe-determined factors, may account for the motor and vocal tic activity of TS. Another consequence of the chronically lower tonic DA is that it may explain presynaptic upregulation of enzymes such as elevated DOPA decarboxylase and other precursors of DA; this is apparently true in SCZ (Reith et al, 1994) and perhaps in TS as well (Ernst et al, 1999). 
Another potential factor that could contribute to the increase in $\mathrm{DA}_{\text {rel }}$ observed here would be an increase in the DA innervation. Thus, a simulation of DA dynamics with increased innervation (ie increased levels of type 2 vesicular monoamine transporter (VMAT2)) using a model from Gjedde (2003) has projected that increased VMAT2 could contribute to increased synaptic DA. This is consistent with previous work by Albin et al (2003) who reported small increases in the binding of the VMAT2 ligand $\left[{ }^{11} \mathrm{C}\right]$ dihydrotetrabenazine (DTBZ) among TS patients when compared to controls. In their study, Albin's group saw a significant increase in DTBZ binding (using voxel-by-voxel analysis) in right ventral striatum (effect size of 0.55). In our study, we also see a significant increase in occupancy of similar effect size (0.6), but we see this increase bilaterally, in both left and right ventral striatum (with a weaker significance in the left ventral striatum.) The bilateral nature of our result and equivalent effect size suggest that other factors outside of increased innervation play a role in the change of occupancy we see. Therefore, based on our tonic-phasic model of TS for DA, we propose one mechanism may be that the low tonic $\mathrm{DA}_{\text {rel }}$ leads to unchecked phasic $\mathrm{DA}_{\text {rel }}$, as tonic $\mathrm{DA}_{\text {rel }}$ normally inhibits phasic $\mathrm{DA}_{\text {rel }}$.

\section{5-HT and DA Relationships}

We were also able to introduce the findings of $5-\mathrm{HT}_{2 \mathrm{~A}} \mathrm{R}$ and SERT measures in TS, which are particularly relevant, because of the high prevalence of co-morbid OCD. We demonstrated SERT reductions in the entire 11-subject TS alone group, as well as in those TS + OCD subjects. Our findings are consistent with those of Muller-Vahl et al (2005); although this was a SPECT study using the tracer $\left[{ }^{123} \mathrm{I}\right] \beta$-CIT, and other studies showed increased (Pogarell et al, 2003) or unchanged (Simpson et al, 2003) SERT. However, our study also includes the concomitant $5-\mathrm{HT}_{2 \mathrm{~A}} \mathrm{R}$ measure, indicative of a trend for elevations in $5-\mathrm{HT}_{2 \mathrm{~A}} \mathrm{BP}$.

5 -HT abnormalities have been hypothesized in TS, although there are conflicting reports regarding 5-HT metabolism (Comings, 1990; Leckman et al, 1984). Some abnormalities that have been hypothesized to be related to co-morbidity with OCD include decreased SERT in platelets (Weizman et al, 1992).

There is increasing pharmacological evidence implicating the 5-HT system in the pathophysiology of TS, which does not seem to be limited to a co-morbid OCD. Studies have shown that TS patients who are resistant to neuroleptics show a reduction in tic severity with risperidone, which has combined 5- $\mathrm{HT}_{2}$ and $\mathrm{D}_{2}$ antagonism properties (Bruun and Budman, 1996). A negative correlation has been shown between vocal tics and SERT (Heinz et al, 1998). There are few studies on OCD or TS + OCD that clearly delineate the 5-HT abnormalities, and imaging studies have reported inconsistent results. For example, one study demonstrated significantly reduced SERT in midbrain/brainstem in TS subjects with co-morbid OCD (Stengler-Wenzke et al, 2004), while two others showed increased (Pogarell et al, 2003) or unchanged (Simpson et al, 2003) SERT. One study examined SERT in TS and found reductions mainly in TS + OCD (Muller-Vahl et al, 2005). In addition, Haugbol et al (2007) suggest that $5-\mathrm{HT}_{2 \mathrm{~A}} \mathrm{R}$ may be elevated in TS.
To these earlier findings, we can now add two additional sets of results from our study. Although in a smaller subfraction of our subjects, these results are provocative and give rise to a proposed model of DA and 5-HT interactions, which we will describe below.

\section{Effect of TS and OCD on DA $\mathrm{A}_{\text {rel }}$}

The initial TS subject group was subdivided into co-morbid subjects (TS + OCD, $n=10$ ) and subjects with TS symptoms only (TS-OCD, $n=4$ ). A one-way ANOVA showed a significant effect of OCD diagnosis on the $\mathrm{DA}_{\text {rel }}$ values of TS subjects in the ventral striatum $(p<0.05)$. Specifically, post hoc contrasts showed that $\mathrm{DA}_{\text {rel }}$ was significantly elevated in TS + OCD subjects $(p<0.05)$, as compared with normal controls $(n=8)$, in the left ventral striatum for both the SRTM and RTGA methods (Figure 5). DA rel $_{\text {in TS-OCD }}$ subjects were elevated as compared to controls, but lower than that seen in TS + OCD; however, these contrasts were only weakly significant $(p=0.5)$.

More provocative, however, are the results of a subset of our sample, which consists of three TS + OCD subjects who completed the $\mathrm{DA}_{\text {rel }}$ and 5-HT PET scans within 1 year. Three TS subjects with co-morbid OCD (based on Y-BOCS scores, Goodman et al, 1989a, b; and SCID diagnoses (First et al, 1994) completed three DA and two 5-HT PET scans. For these TS $+\mathrm{OCD}$ subjects, $\mathrm{DA}_{\text {rel }}$ and $5-\mathrm{HT}_{2 \mathrm{~A}} \mathrm{BP}$ were elevated in comparison with TS-OCD subjects $(p<0.05)$, and SERT BP was lower, in comparison with normal controls $(p=0.05$; Figure 6$)$.

If the primary deficiency in TS with OCD is 5-HT depletion, then this co-morbid state would produce a compensatory increase in $5-\mathrm{HT}_{2 \mathrm{~A}} \mathrm{BP}$ and thereby reduce SERT. By inference from the therapeutic response with SSRIs, which increase intrasynaptic 5-HT and improve OCD symptoms, it is reasonable to speculate that $5-\mathrm{HT}_{2 \mathrm{~A}} \mathrm{BP}$ is increased, and SERT would be decreased, in TS + OCD and $\mathrm{OCD}$ alone. These findings, combined with the tendency for an upregulation of $5-\mathrm{HT}_{2 \mathrm{~A}} \mathrm{BP}$ (though this increase is not significant and $p>0.1$ ), gives rise to the following proposed models of DA and 5-HT interaction, where a 5-HT deficit could give rise to an increase in phasic $\mathrm{DA}_{\text {rel }}$ (Figure 7 describes the model graphically).

\section{5-HT and DA Interaction: 5-HT Decrease as Primary Deficit Leading to Increased $\mathrm{DA}_{\text {rel }}$}

If 5-HT were reduced in the TS + OCD subjects, SERT would be downregulated to compensate for the intrasynaptic 5-HT deficit, and $5-\mathrm{HT}_{2 \mathrm{~A}} \mathrm{R}$ would be upregulated postsynaptically to increase sensitivity for the remaining 5-HT. Similarly, because of the known literature demonstrating the relationship between $5-\mathrm{HT}_{2 \mathrm{~A}} \mathrm{R}$ antagonists and DA (Porras et al, 2002; Schmidt et al, 1994), this upregulated $5-\mathrm{HT}_{2 \mathrm{~A}} \mathrm{R}$ and decreased 5-HT could further enhance $\mathrm{DA}_{\text {rel }}$. Although, to date, we have studied three of our subjects at both DA and 5-HT systems (Figure 5), it does provide further preliminary support for this concept. Thus, our results are consistent with the effects on $\mathrm{DA}_{\text {rel }}$ of concomitant OCD with TS, and may help explain some of the pathophysiology of this comorbidity (Figure 6). 

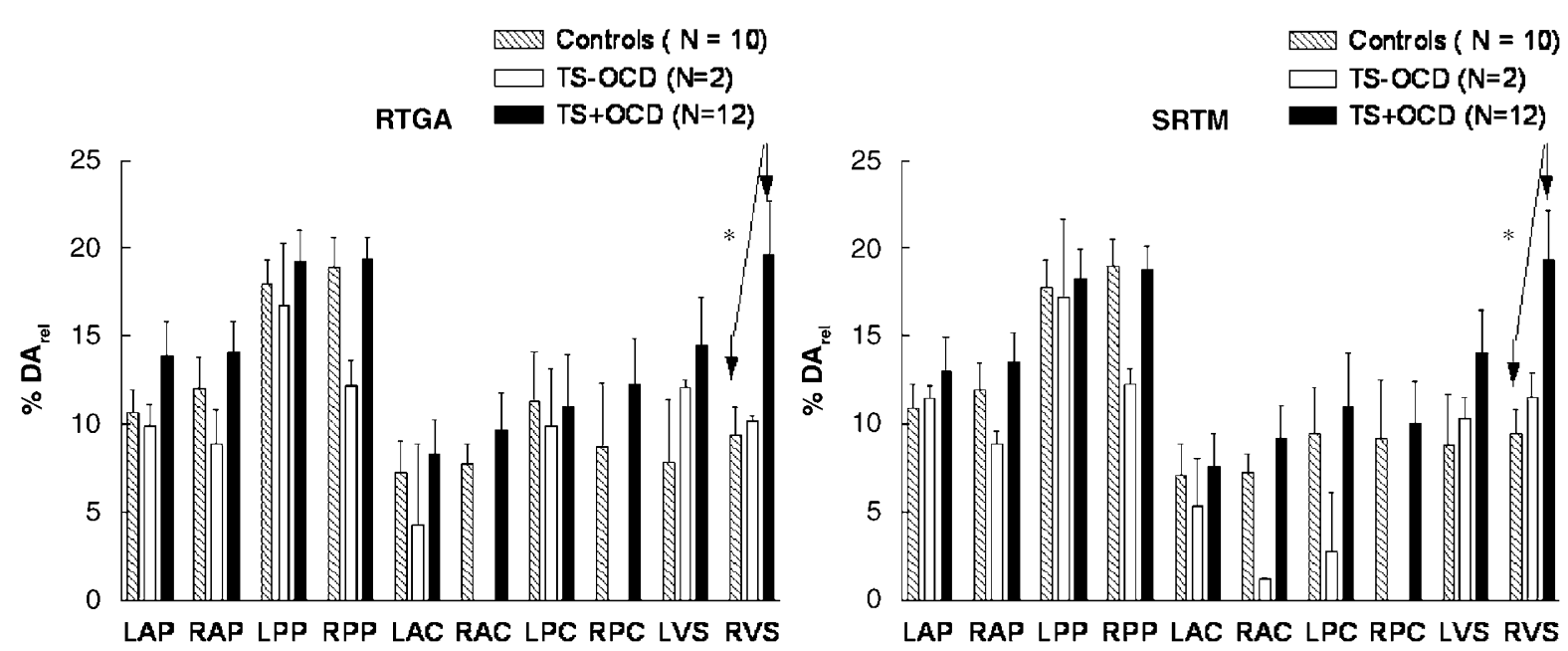

Figure 5 Amphetamine (AMP)-induced $D_{\text {rel }}$ in TS + OCD and TS-OCD subjects and normal controls, by the SRTM and RTGA methods. AMPinduced dopamine release (DA rel) was measured by the simplified reference tissue method (SRTM; Lammerstma and Hume, 1996), and the reference tissue graphical analysis (RTGA; Logan et al, 1996) in subjects with Tourette syndrome (TS), with and without obsessive-compulsive disorder (OCD), and normal controls. A significant increase in $\mathrm{DA}_{\text {rel }}$ was seen in TS + OCD, as compared with normal controls $(* p<0.05)$. Both analyses methods confirm the concept that AMP-induced $D_{\text {rel }}$ in the left ventral striatum is greater in TS +OCD $>$ TS-OCD > normal controls.
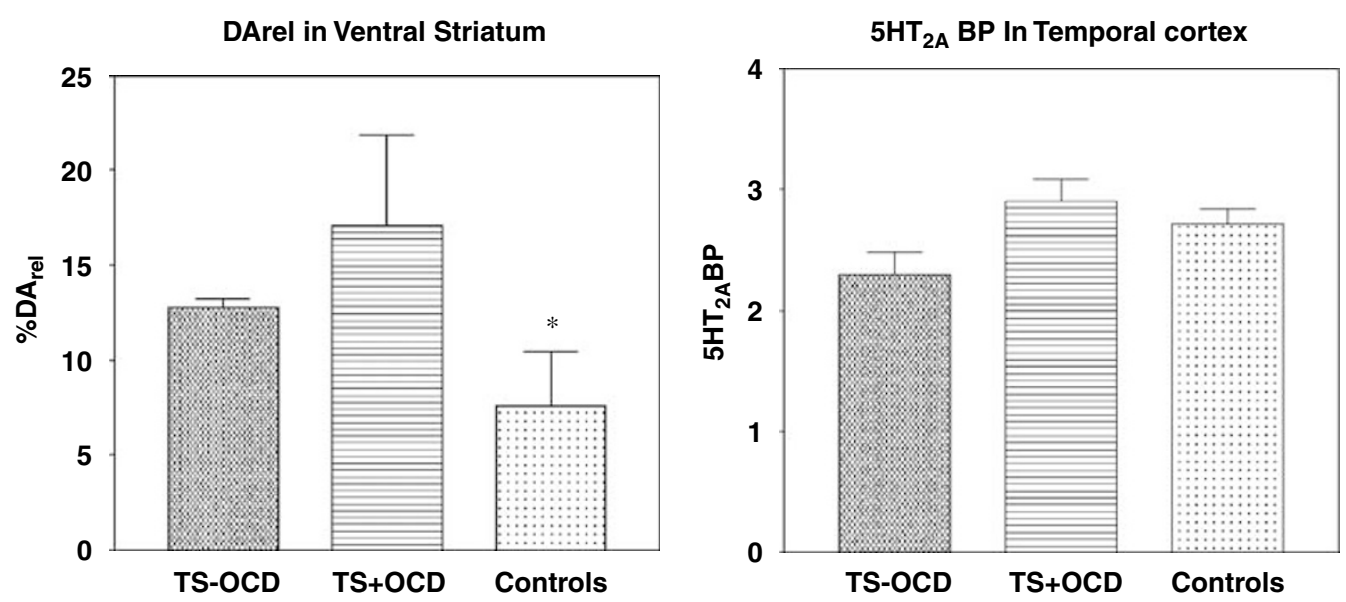

Figure 6 Elevation of AMP-induced $D A_{\text {rel }}$ and $5-\mathrm{HT}_{2 A} \mathrm{R}$ binding potential $(\mathrm{BP})$ in $\mathrm{TS}+\mathrm{OCD}$ and TS-OCD subjects, and normal controls. A subset of subjects with Tourette syndrome and OCD (TS + OCD), who completed all dopamine and serotonin PET scans, were compared with the TS-OCD subjects and normal controls from the same study. In the three TS + OCD subjects, there was a significant elevation of DA $A_{\text {rel, }}$ as compared with normal controls $(p=0.05)(*)$, and a significant elevation of $5-\mathrm{HT}_{2 \mathrm{~A}} \mathrm{R}$ BP, as compared with the TS-OCD subjects $(p=0.05)(*)$.

\section{5-HT and DA Interaction: Lack of SERT Compensation Leading to Increased $\mathrm{DA}_{\text {rel }}$}

An alternative explanation is that there is a 5 -HT deficit in OCD, but SERT is unable to compensate for this decrease. Thus, the failure of the SERT compensatory mechanism drives intrasynpatic 5-HT even lower, which may lead to even higher $\mathrm{DA}_{\text {rel }}$. This would be consistent with the trend in our data for TS + OCD subjects to have slightly higher SERT than TS-OCD subjects. In this alternative mechanism, 5-HT normally has a controlling effect on phasic DA, by controlling DA neuron firing directly. Lodge and Grace (2006) have shown that only spontaneously firing DA neurons can burst fire (ie create a phasic DA response), and that changes in the population of spontaneously firing DA neurons can modulate the burst (phasic) response. A deficit of 5-HT would lead to an increase in the population of spontaneously firing neurons. Normally, a downregulation of SERT could compensate for this increase. However, if SERT is unable to downregulate in TS + OCD, this would cause 5-HT levels to decrease even further and lead to an even higher $\mathrm{DA}_{\text {rel }}$, via the increase in spontaneously firing DA neurons.

In summary, we have reproduced our initial reported findings (Singer et al, 2002) in a sample of twice the initial size, and have augmented our initial findings by using a higher resolution tomograph. We have demonstrated SERT reductions consistent with one other published study, but have added evidence of concomitant $\mathrm{DA}_{\text {rel }}$ and $5-\mathrm{HT}_{2 \mathrm{~A}} \mathrm{R}$ abnormalities that could serve as the basis for a neurochemical model of DA-5-HT interaction in TS with concomitant OCD. Future directions include the role of DA and attention deficit disorder with or without concomitant OCD in TS. Further understanding of this pathophysiology will be essential in developing potential pharmacologic treatments. 
a

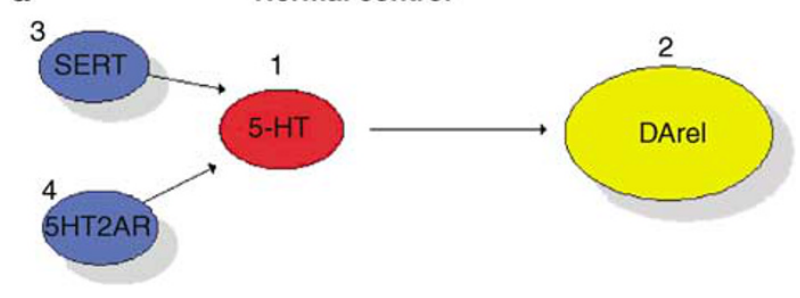

b

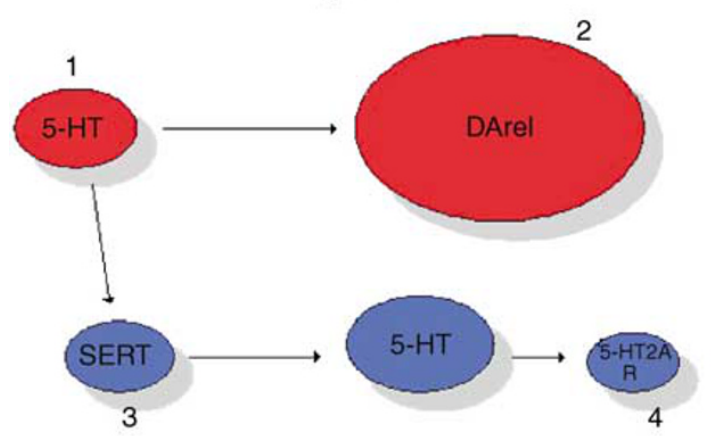

C

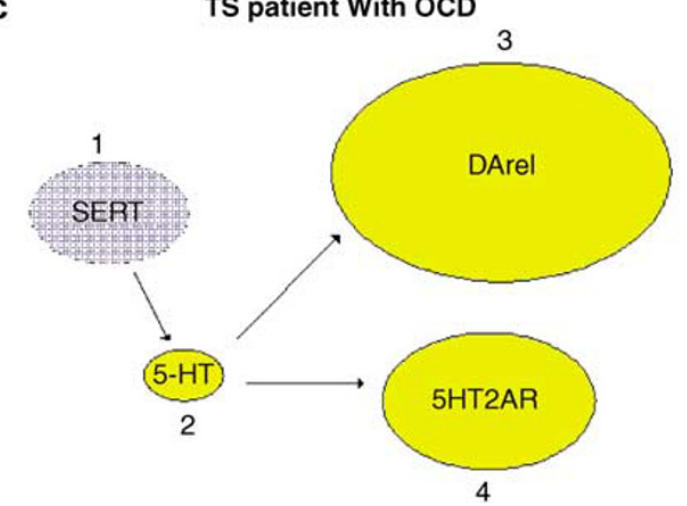

Figure 7 DA and 5-HT dynamics in TS + OCD and TS-OCD. (a) Normal control: in a healthy brain, 5-HT (I) levels can downregulate DA (2). In turn, 5-HT can be regulated by SERT (3). The brain can regulate 5HT levels by changing SERT (3) and modulate the impact of 5 -HT by altering $5-\mathrm{HT} 2_{A} \mathrm{R}(4)$ levels. These compensatory mechanisms are altered in TS and TS with OCD, as shown below. (b) TS patient (no OCD): in a patient with TS, we propose that the primary deficit is diminished 5-HT levels (I) resulting in an upregulation of $\mathrm{DA}_{\text {rel }}$ (2). In response to diminished 5-HT, SERT levels (3) decrease to compensate, allowing more $5-\mathrm{HT}$ to remain in the synapse, the higher intrasynaptic 5-HT in turn leads to a decrease in 5-HT2 $2_{A} \mathrm{R}$ numbers (4). (c) TS Patient with OCD: in a patient with both TS and OCD, SERT ( 1 ) fails to compensate, and as a result, there are substantially lower levels of 5-HT (2). As a result, there is an even greater hyper-responsive $\mathrm{DA}_{\text {rel }}$ (3). Additionally, because of the lowered 5-HT, there is a compensatory increase in $5-\mathrm{HT} 2_{\mathrm{A}} \mathrm{R}$ number (4).

\section{ACKNOWLEDGEMENTS}

This work was supported by grant from PHS Grants RO1 MH078175, NS38927, K24 DA00412, RO1 AA12839. HSS currently has grant support from UCB Pharma, and has previously served as a consultant for Penwest and Shire. We thank the excellent editorial assistance of Melinda Roberson, $\mathrm{PhD}$.

We also thank the Johns Hopkins Hospital PET Center and Biomedical Cyclotron staff, and L. Smith, M Thomas, and $\mathrm{K}$ Warren.

\section{REFERENCES}

Albin RL, Koeppe RA, Bohnen NI, Nichols TE, Meyer P, Wernette $\mathrm{K}$ et al (2003). Increased ventral striatal monoaminergic innervation in Tourette syndrome. Neurology 61: 310-315.

American Psychiatric Association (2004). Diagnostic and Statistical Manual of Mental Disorders, 4th edn. Text revision (DSM$\mathrm{IV}^{-\mathrm{TM}^{\mathrm{TM}}}{ }^{\mathrm{M}}$, American Psychiatric Association: Washington, DC.

Baumann MH, Danos P, Krell D, Diekmann S, Leschinger A, Stauch $\mathrm{R}$ et al (1999). Reduced volume of limbic systemaffiliated basal ganglia in mood disorders: preliminary data from a postmortem study. J Neuropsychiatry Clin Neurosci 11: 71-78.

Bruun RD, Budman CL (1996). Risperidone as a treatment for Tourette's syndrome. J Clin Psychiatry 57: 29-31.

Butler IJ, Koslow SH, Seifert Jr WE, Caprioli RM, Singer HS (1979). Biogenic amine metabolism in Tourette syndrome. Ann Neurol 6: 37-39.

Comings DE (1990). Blood serotonin and tryptophan in Tourette Syndrome. Am J Med Genet 36: 418-430.

Ehrin E, Farde L, de Paulis T, Eriksson L, Greitz T, Johnstrom P et al (1985). Preparation of ${ }^{11} \mathrm{C}$-labelled Raclopride, a new potent dopamine receptor antagonist: preliminary PET studies of cerebral dopamine receptors in the monkey. Int J Appl Radiat Isot 36: 269-273.

Ernst M, Zametkin AJ, Jons PH, Matochik JA, Pascualvaca D, Cohen RM (1999). High presynaptic dopaminergic activity in children with Tourette's disorder. J Am Acad Child Adolesc Psychiatry 38: 86-94.

Farde L, Eriksson L, Blomquist G, Halldin C (1989). Kinetic analysis of central [11C]raclopride binding to D2-dopamine receptors studied by PET: a comparison to the equilibrium analysis. J Cereb Blood Flow Metab 9: 696-708.

First MB, Spitzer RL, Gibbon M, Williams JBW (1994). Structured Clinical Interview for DSM-IV Axis I Disorders, Clinician Version (SCID-CV). American Psychiatric Press: Washington, DC.

Gjedde A (2003). Modeling metabolite and tracer kinetics. In: Feinendegen LE, Shreeve WW, Eckelman WC, Bahk Y-W, Wagner Jr HN (eds). Molecular Nuclear Medicine, Chapter 7. Springer-Verlag: Berlin, Heidelberg. pp 121-169.

Gjedde A, Wong DF (1998). No acute effect of amphetamine on dopamine receptor binding potential in healthy subjects or patients in schizophrenia. NeuroImage 7: A44 (abstract).

Goodman WK, Price LH, Rasmussen SA, Mazure C, Delgado P, Heninger GR et al (1989a). The Yale-Brown Obsessive Compulsive Scale. II. Validity. Arch Gen Psychiatry 46: 1012-1016.

Goodman WK, Price LH, Rasmussen SA, Mazure C, Fleischmann RL, Hill CL et al (1989b). The Yale-Brown Obsessive Compulsive Scale. I. Development, use, and reliability. Arch Gen Psychiatry 46: 1006-1011.

Grace AA (1991). Phasic versus tonic dopamine release and the modulation of dopamine system responsivity: a hypothesis for the etiology of schizophrenia. Neuroscience 41: 1-24.

Grace AA (1993). Cortical regulation of subcortical dopamine systems and its possible relevance to schizophrenia. J Neural Transm 91: 111-134.

Grace AA (1995). The tonic/phasic model of dopamine system regulation: its relevance for understanding how stimulant abuse can alter basal ganglia function. Drug Alcohol Depend 37: 111-129.

Guy W (1976). ECDEU Assessment Manual for Psychopharmacology Revised, DHEW Publication No. (ADM) 76-338 US Department of Health, Education, and Welfare: Rockville, MD, 217-222.

Haugbol S, Pinborg LH, Regeur L, Hansen ES, Bolwig TG, Nielsen FA et al. (2007). Cerebral 5-HT2A receptor binding is increased in patients with Tourette's syndrome. Int J Neuropsychopharmacol 10: 245-252.

Heinz A, Knable MB, Wolf SS, Jones DW, Gorey JG, Hyde TM et al (1998). Tourette's syndrome: [I-123]beta-CIT SPECT correlates of vocal tic severity. Neurology 51: 1069-1074. 
Ichise M, Liow JS, Lu JQ, Takano A, Model K, Toyama $\mathrm{H}$ et al (2003). Linearized reference tissue oparametric imaging methods: application to $\left[{ }^{11} \mathrm{C}\right] \mathrm{DASB}$ positron emission tomography studies of the serotonin transporter in human brain. J Cereb Blood Flow Metab 23: 1096-1112.

Ichise M, Toyama H, Innis RB, Carson RE (2002). Strategies to improve neuroreceptor parameter estimation by linear regression analysis. J Cereb Blood Flow Metab 22: 1271-1281.

Karachi C, Francois C, Parain K, Bardinet E, Tande D, Hirsch E et al (2002). Three-dimensional cartography of functional territories in the human striatopallidal complex by using calbindin immunoreactivity. J Comp Neurol 450: 122-134.

Lammerstma AA, Hume SP (1996). Simplified reference tissue model for PET receptor studies. NeuroImage 4: 153-158.

Laruelle M, Abi-Dargham A, Gil R, Kegeles L, Innis R (1999). Increased dopamine transmission in schizophrenia: relationship to illness phases. Biol Psychiatry 46: 56-72.

Laruelle M, Abi-Dargham A, Van Dyck C, Gil R, D’Souza C, Erdos J et al (1996). Single photon emission computerized tomography imaging of amphetamine-induced dopamine release in drug-free schizophrenic subjects. Proc Natl Acad Sci USA 93: 9235-9240.

Leckman JF, Anderson GM, Cohen DJ, Ort S, Harcherik DF, Hoder EL et al (1984). Whole blood serotonin and tryptophan levels in Tourette's disorder: effects of acute and chronic clonidine treatment. Life Sci 35: 2497-2503.

Leckman JF, Riddle MA, Hardin MT, Ort SI, Swartz KL, Stevenson J et al (1989). The Yale Global Tic Severity Scale: initial testing of a clinician rated scale of tic severity. J Am Acad Child Adolesc Psychiatry 28: 566-573.

Lodge DJ, Grace AA (2006). The hippocampus modulates dopamine neuron responsivity by regulating the intensity of phasic neuron activation. Neuropsychopharmacology 31: 1356-1361.

Logan J, Fowler JS, Volkow ND, Wang GJ, Ding YS, Alexoff D (1996). Distribution volume ratios without blood sampling from graphical analysis of PET data. J Cereb Blood Flow Metab 16: 834-840.

Malison RT, McDougle CJ, van Dyck CH, Scahill L, Baldwin RM, Seibyl JP et al (1995). [ $\left.{ }^{123} \mathrm{I}\right] \beta$-CIT SPECT imaging of striatal dopamine transporter binding in Tourette's disorder. $A m \mathrm{~J}$ Psychiatry 152: 1359-1361.

Martinez D, Slifstein M, Broft A, Mawlawi T, Hwang DR, Huang YY et al (2003). Imaging human mesolimbic dopamine transmission with positron emission tomography. Part II: amphetamineinduced dopamine release in the functional subdivisions of the striatum. J Cereb Blood Flow Metab 23: 285-300.

McCann UD, Szabo Z, Seckin E, Rosenblatt P, Mathews WB, Ravert HT et al (2005). Quantitative PET studies of the serotonin transporter in MDMA users and controls using [ $\left.{ }^{11} \mathrm{C}\right] \mathrm{McN} 5652$ and $\left[{ }^{11} \mathrm{C}\right] \mathrm{DASB}$. Neuropsychopharmacology 30: 1741-1750.

McDougle CJ, Epperson CN, Pelton GH, Wasylink S, Price LH (2000). A double-blind, placebo-controlled study of risperidone addition in serotonin reuptake inhibitor-refractory obsessivecompulsive disorder. Arch Gen Psychiatry 57: 794-801.

Meyer JH, Gunn RN, Myers R, Grasby PM (1999). Assessment of spatial normalization of PET ligand images using ligand-specific templates. NeuroImage 9: 545-553.

Muller-Vahl KR, Meyer GJ, Knapp WH, Emrich HM, Gielow P, Brucke $\mathrm{T}$ et al (2005). Serotonin transporter binding in Tourette syndrome. Neurosci Lett 385: 120-125.

Murray JB (1997). Psychophysiological aspects of Tourette's syndrome. J Psychol 131: 615-626.

O'Donnell P, Grace AA (1994). Tonic $\mathrm{D}_{2}$-mediated attenuation of cortical excitation in nucleus accumbens neurons recorded in vitro. Brain Res 634: 105-112.

Overall JE, Gorham DR (1962). The Brief Psychiatric Rating Scale. Psychol Rep 10: 799-812.

Pfanner C, Marazziti D, Dell'Osso L, Presta S, Gemignani A, Milanfranchi A et al (2000). Risperidone augmentation in refractory obsessive-compulsive disorder: an open-label study. Int Clin Psychopharmacol 15: 297-301.

Pogarell O, Hamann C, Popperl G, Juckel G, Chouker M, Zaudig M et al (2003). Elevated brain serotonin transporter availability in patients with obsessive-compulsive disorder. Biol Psychiatry 54: 1406-1413.

Porras G, Di Matteo V, Fracasso C, Lucas G, De Deurwaerdere P, Caccia $S$ et al (2002). 5-HT2A and 5-HT2C/2B receptor subtypes modulate dopamine release induced in vivo by amphetamine and morphine in both the rat nucleus accumbens and striatum. Neuropsychopharmacology 26: 311-324.

Reith J, Benkelfat C, Sherwin A, Yasuhara Y, Kuwabara H, Andermann F et al (1994). Elevated DOPA decarboxylase activity in living brain of patients with psychosis. Proc Natl Acad Sci USA 91: 11651-11654.

Scahill L, Erenberg G, Berlin Jr CM, Budman C, Coffey BJ, Jankovic J et al (2006). Tourette Syndrome Association Medical Advisory Board: Practice Committee Contemporary assessment and pharmacotherapy of Tourette syndrome. NeuroRx 3: 192-206.

Schmidt CJ, Sullivan CK, Fadayel GM (1994). Blocakde of striatal 5 HT2 receptors reduces the increase in extracellular concentrations of dopamine produced by the amphetamine analogue 3,4metylenedioxymethamphetamine. J Neurochem 62: 1382-1389.

Shytle RD, Silver AA, Sanberg PR (2000). Comorbid bipolar disorder in Tourette's syndrome responds to the nicotinic receptor antagonist mecamylamine (Inversine). Biol Psychiatry 48: $1028-1031$.

Silver AA, Shytle RD, Sanberg PR (2000). Mecamylamine in Tourette's syndrome: a two-year retrospective case study. J Child Adolesc Psychopharmacol 10: 59-68.

Silvestri R, Raffaele M, De Domenico P, Tisano A, Lagana A, Di Perri R (1994). Serotoninergic agents in the treatment of Gilles de la Tourette's syndrome. Acta Neurol 16: 58-63.

Simpson HB, Lombardo I, Slifstein M, Huang HY, Hwang DR, AbiDargham A et al (2003). Serotonin transporters in obsessivecompulsive disorder: a positron emission tomography study with [(11)C]McN 5652. Biol Psychiatry 54: 1414-1421.

Singer HS (2001). The treatment of tics. Curr Neurol Neurosci Rep 1: 195-202.

Singer HS, Butler IJ, Tune LE, Seifert Jr WF, Coyle JT (1982). Dopaminergic dysfunction in Tourette syndrome. Ann Neurol 12: $361-366$.

Singer HS, Reiss AL, Brown JE, Aylward EH, Shih B, Chee E et al (1993). Volumetric MRI changes in basal ganglia of children with Tourettes-syndrome. Neurology 43: 950-956.

Singer HS, Szymanski S, Giuliano J, Yokoi F, Dogan AS, Brasic JR et al (2002). Elevated intrasynaptic dopamine release in Tourette's syndrome measured by PET. Am J Psychiatry 159: 1329-1336.

Singer HS, Hahn IH, Moran TH (1991). Abnormal dopamine uptake sites in postmortem striatum from patients with Tourette's syndrome. Ann Neurol 30: 558-562.

Sölling T, Brust P, Cunningham VJ, Wong DF, Gjedde A (1997). True equilibrium bolus estimation (TREMBLE) confirms rapid transient equilibrium. NeuroImage 5: A29.

Stengler-Wenzke K, Muller U, Angermeyer MC, Sabri O, Hesse S (2004). Reduced serotonin transporter-availability in obsessivecompulsive disorder (OCD). Eur Arch Psychiatry Clin Neurosci 254: 252-255.

Szabo Z, McCann UD, Wilson AA, Scheffel U, Owonikoko T, Mathews WB et al (2002). Comparison of (+)-(11)C-McN5652 and (11)C-DASB as serotonin transporter radioligands under various experimental conditions. J Nucl Med 43: 678-692.

Weizman A, Mandel A, Barber Y, Weitz R, Cohen A, Mester R et al (1992). Decreased platelet imipramine binding in Tourette syndrome children with obsessive-compulsive disorder. Biol Psychiatry 31: 705-711.

Wender PH (1995). Attention-Deficit Hyperactivity Disorder in Adults. Oxford University Press: New York. 


\section{DA and $5 H T$ neurotransmission in TS}

West AR, Grace AA (2002). Opposite influences of endogenous dopamine $\mathrm{D}_{1}$ and $\mathrm{D}_{2}$ receptors activation on activity states and electrophysiological properties of striatal neurons: studies combining in vivo intracellular recordings and reverse microdialysis. J Neurosci 22: 294-304.

Wightman RM, Robinson DR (2002). Transient changes in mesolimbic dopamine and their association with 'reward'. J Neurochem 82: 721-735.

Wong DF, Brasic JR, Kuwabara H, Zhou Y, Schretlen D, Kumar A et al (2005). Abnormalities of dopamine and serotonin neuroreceptors documented with PET in Tourette syndrome. J Nucl Med 48: 182P (abstract).

Wong DF, Singer HS, Brandt J, Shaya E, Chen C, Brown J et al (1997). $\mathrm{D}_{2}$-like dopamine receptor density in Tourette syndrome measured by PET. J Nucl Med 38: 1243-1247.

Wong DF, Solling T, Yokoi F, Gjedde A (1998). Quantification of extracellular dopamine release in schizophrenia and cocaine use by means of TREMBLE. In: Carson RE, Herscovitch P, DaubeWitherspoon ME (eds). Quantitative Functional Brain Imaging with Positron Emission Tomography, 1st edn. Academic Press: San Diego, California. pp 463-468.

Wong DF, Yung B, Dannals RF, Shaya EK, Ravert HT, Chen CA et al (1993). In vivo imaging of baboon and human dopamine transporters by positron emission tomography, using $\left[{ }^{11} \mathrm{C}\right] \mathrm{WIN}$ 35,428. Synapse 15: 130-142.

Zhou Y, Brasic J, Dogan AS, Ye W, Crabb AH, Hilton J et al (2004a). A robust parametric imaging algorithm to quantify serotonin receptor and transporter binding in human brain using ${ }^{11} \mathrm{C}-\mathrm{MDL} 100,907$ and $(+)^{11} \mathrm{C}-\mathrm{MCN} 5652$ dynamic PET. $J$ Nucl Med 45(Suppl 5): 395P-396P (abstract).

Zhou Y, Brasic J, Endres CJ, Kuwabara H, Kimes A, Contoreggi C et al (2002a). Binding potential image based statistical mapping for detection of dopamine release by $\left[{ }^{11} \mathrm{C}\right]$ raclopride dynamic PET. NeuroImage 16: S91.

Zhou Y, Brasic JR, Ye WG, Dogan AS, Hilton J, Singer HS et al (2004b). Quantification of cerebral serotonin binding in normal controls and subjects with Tourette's syndrome using [C11]MDL 100,907 and (+)[C-11] McN 5652 dynamic PET with parametric imaging approach. NeuroImage 22: T98-T99.

Zhou Y, Endres CJ, Brasic JR, Huang SC, Wong DF (2003). Linear regression with spatial constraint to generate parametric images of ligand-receptor dynamic PET studies with a simplified reference tissue model. NeuroImage 18: 975-989.

Zhou Y, Huang SC, Bergsneider M, Wong DF (2002b). Improved parametric image generation using spatial-temporal analysis of dynamic PET studies. NeuroImage 15: 697-707. 